Review Article

\title{
A Review on Antibacterial, Antiviral, and Antifungal Activity of Curcumin
}

\author{
Soheil Zorofchian Moghadamtousi, ${ }^{1}$ Habsah Abdul Kadir, ${ }^{1}$ \\ Pouya Hassandarvish, ${ }^{2}$ Hassan Tajik, ${ }^{3}$ Sazaly Abubakar, ${ }^{2}$ and Keivan Zandii ${ }^{2,4}$ \\ ${ }^{1}$ Biomolecular Research Group, Biochemistry Program, Institute of Biological Sciences, Faculty of Science, \\ University of Malaya, 50603 Kuala Lumpur, Malaysia \\ ${ }^{2}$ Tropical Infectious Disease Research and Education Center (TIDREC), Department of Medical Microbiology, \\ Faculty of Medicine, University of Malaya, 50603 Kuala Lumpur, Malaysia \\ ${ }^{3}$ Department of Chemistry, Faculty of Sciences, Guilan University, Rasht, Iran \\ ${ }^{4}$ Persian Gulf Marine Biotechnology Research Center, Bushehr University of Medical Sciences, Bushehr 3631, Iran \\ Correspondence should be addressed to Keivan Zandi; keivan@um.edu.my
}

Received 21 January 2014; Accepted 28 March 2014; Published 29 April 2014

Academic Editor: José Carlos Tavares Carvalho

Copyright (C) 2014 Soheil Zorofchian Moghadamtousi et al. This is an open access article distributed under the Creative Commons Attribution License, which permits unrestricted use, distribution, and reproduction in any medium, provided the original work is properly cited.

\begin{abstract}
Curcuma longa L. (Zingiberaceae family) and its polyphenolic compound curcumin have been subjected to a variety of antimicrobial investigations due to extensive traditional uses and low side effects. Antimicrobial activities for curcumin and rhizome extract of C. longa against different bacteria, viruses, fungi, and parasites have been reported. The promising results for antimicrobial activity of curcumin made it a good candidate to enhance the inhibitory effect of existing antimicrobial agents through synergism. Indeed, different investigations have been done to increase the antimicrobial activity of curcumin, including synthesis of different chemical derivatives to increase its water solubility as well ass cell up take of curcumin. This review aims to summarize previous antimicrobial studies of curcumin towards its application in the future studies as a natural antimicrobial agent.
\end{abstract}

\section{Introduction}

Curcumin or diferuloylmethane with chemical formula of (1,7-bis(4-hydroxy-3-methoxyphenyl)-1,6-heptadiene-3,5dione) (Figure 1) and other curcuminoids constitute the main phytochemicals of Curcuma longa L. (Zingiberaceae family) rhizome with the common name of turmeric [1]. This polyphenolic compound due to a variety of biological activities has been gained significant attention of researches all over the world [2-5]. Turmeric, an ancient coloring spice of Asia, as the main source of curcumin is traditionally used for many remedies [6]. As shown in Figure 2, curcumin due to a variety of specific characterizations is in interest of scientists in recent years. As many other plant materials, there are differences in the curcumin content for the Curcuma longa from different geographical regions and it could be due to hybridization with other Curcuma species which could be important fact to choose the plant with higher content of curcumin [4].

Curcuma longa rhizome has been traditionally used as antimicrobial agent as well as an insect repellant [7]. Several studies have reported the broad-spectrum antimicrobial activity for curcumin including antibacterial, antiviral, antifungal, and antimalarial activities. Because of the extended antimicrobial activity of curcumin and safety property even at high doses (12 g/day) assessed by clinical trials in human, it was used as a structural sample to design the new antimicrobial agents with modified and increased antimicrobial activities through the synthesis of various derivatives related to curcumin $[8,9]$. It was even studied as an antimicrobial agent suitable for textile materials. Results showed that curcumin in combination with aloe vera and chitosan could 


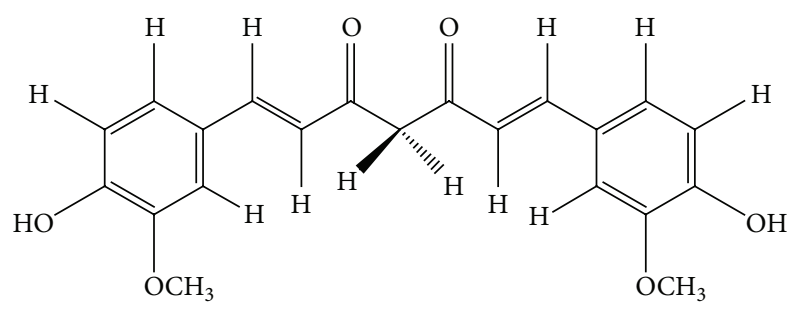

FIGURE 1: Chemical structure of curcumin.

be a potential suppressor for microbial growth in cotton, wool, and rabbit hair assessed by the exhaustion method [10]. Either the continuous or batch dyeing process with curcumin provided textiles with antimicrobial properties beside the color. Curcumin finished wool had semidurable antimicrobial activity, less durable to light exposure than home laundering with $45 \%$ and $30 \%$ inhibition rates against Staphylococcus aureus and Escherichia coli, respectively, after 30 cycles of home laundering [11]. Mixture of curcumin with other antimicrobial agents is used for the development of antimicrobial skin gels and emulsions with improved skin protection and wound dressing properties [12]. Composition of curcumin with hydrogel silver nanoparticles is used to increase the function of hydrogel silver nanocomposites as marked substances for antimicrobial applications and wound dressing [12]. Curcumin-loaded myristic acid microemulsion with the $0.86 \mu \mathrm{g} / \mathrm{mL}$ of curcumin suitable for skin consumption inhibited $50 \%$ of the S. epidermidis growth as one of the nosocomial infectious agents. It showed 12-fold stronger inhibitory effect compared to curcumin activity dissolved in dimethyl sulfoxide (DMSO) [13].

\section{Antibacterial Activity}

Bacterial infections are among the important infectious diseases. Hence, over 50 years of extensive researches have been launched for achieving new antimicrobial medicines isolated from different sources. Despite progress in development of antibacterial agents, there are still special needs to find new antibacterial agents due to development of multidrug resistant bacteria [14]. The antibacterial study on aqueous extract of C. longa rhizome demonstrated the MIC (minimum inhibitory concentration) value of 4 to $16 \mathrm{~g} / \mathrm{L}$ and MBC (minimum bactericidal concentration) value of 16 to $32 \mathrm{~g} / \mathrm{L}$ against $S$. epidermis ATCC 12228, Staph. aureus ATCC 25923, Klebsiella pneumoniae ATCC 10031, and E. coli ATCC 25922 [15]. The methanol extract of turmeric revealed MIC values of $16 \mu \mathrm{g} / \mathrm{mL}$ and $128 \mu \mathrm{g} / \mathrm{mL}$ against Bacillus subtilis and Staph. aureus, respectively [16]. The study of hexane and ethanol turmeric extract and curcuminoids (from ethyl acetate extract of curcuminoids isolated from C. longa with $86.5 \%$ curcumin value) against 24 pathogenic bacteria isolated from the chicken and shrimp showed the highest antimicrobial activity for ethanol extract with the MIC value of 3.91 to $125 \mathrm{ppt}$ [17]. The hexane and methanol extracts of $C$. longa demonstrated antibacterial effect against
13 bacteria, namely, Vibrio harveyi, V. alginolyticus, V. vulnificus, V. parahaemolyticus, V. cholerae, Bacillus subtilis, $B$. cereus, Aeromonas hydrophila, Streptococcus agalactiae, Staph. aureus, Staph. intermedius, Staph. epidermidis, and Edwardsiella tarda. However, curcuminoids elicited inhibitory activities against 8 bacteria of Str. agalactiae, Staph. intermedius, Staph. epidermidis, Staph. aureus, A. hydrophila, B. subtilis, $B$. cereus, and Ed. tarda. Hexane extract and curcuminoids exhibited the MIC values of 125 to $1000 \mathrm{ppt}$ and 3.91 to $500 \mathrm{ppt}$, respectively [17]. Indeed, it was shown that the addition of $0.3 \%(\mathrm{w} / \mathrm{v})$ of aqueous curcumin extract to the cheese caused the reduction in bacterial counts of Salmonella typhimurium, Pseudomonas aeruginosa, and E. coli 0157:H7. Moreover, it has decreased the Staph. aureus, B. cereus, and Listeria monocytogenes contamination after 14 days of cold storage period [18]. Turmeric oil as a byproduct from curcumin manufacture also was found effective against $B$. subtilis, B. coagulans, B. cereus, Staph. aureus, E. coli, and P. aeruginosa [19]. Curcumin also exhibited inhibitory activity on methicillin-resistant Staph. aureus strains (MRSA) with MIC value of $125-250 \mu \mathrm{g} / \mathrm{mL}$ [20]. The in vitro investigation of 3 new compounds of curcumin, namely, indium curcumin, indium diacetyl curcumin, and diacetyl curcumin, against Staph. aureus, S. epidermis, E. coli, and P. aeruginosa revealed that indium curcumin had a better antibacterial effect compared to curcumin itself and it may be a good compound for further in vivo studies. However, diacetylcurcumin did not exhibit any antibacterial effect against tested bacteria [21]. These results demonstrated promising antibacterial activity for different curcumin derivatives as well. The stability and assembly of FtsZ protofilaments as a crucial factor for bacterial cytokinesis are introduced as a possible drug target for antibacterial agents. Curcumin suppressed the B. subtilis cytokinesis through induction of filamentation. It also without significantly affecting the segregation and organization of the nucleoids markedly suppressed the cytokinetic Z-ring formation in B. subtilis [22]. It was demonstrated that curcumin reduces the bundling of FtsZ protofilaments associated with the binding ability to FtsZ with a dissociation constant of $7.3 \mu \mathrm{M}$. It showed that curcumin via inhibition of assembly dynamics of FtsZ in the Z-ring can possibly suppress the bacterial cell proliferation as one of the probable antibacterial mechanisms of action [22]. The study on E. coli and $B$. subtilis demonstrated that curcumin by the inhibitory effect against FtsZ polymerization could suppress the FtsZ assembly leading to disruption of prokaryotic cell division [23].

Also, curcumin showed significant antibacterial activity with MIC values between 5 and $50 \mu \mathrm{g} / \mathrm{mL}$ against 65 clinical isolates of Helicobacter pylori [41]. Curcumin also has an inhibitory effect on NF- $\kappa \mathrm{B}$ activation and as a result on the release of IL- 8 and cell scattering which led to a reduction in inflammation of gastric tissue as the main consequence for $H$. pylori in stomach. It inhibits the $\mathrm{I} \kappa \mathrm{B} \alpha$ degradation, the activity of NF- $\kappa \mathrm{B}$ DNA-binding and $\mathrm{I} \kappa \mathrm{B}$ kinase $\alpha$ and $\beta$ (IKK $\alpha$ and $\beta$ ) [42]. Indeed, curcumin inhibited the matrix metalloproteinase- 3 and metalloproteinase- 9 activity (MMP3 and MMP-9) as inflammatory molecules involved in $H$. pylori infection in mice and in cell culture with a dose dependent manner [43]. Curcumin showed more efficient 


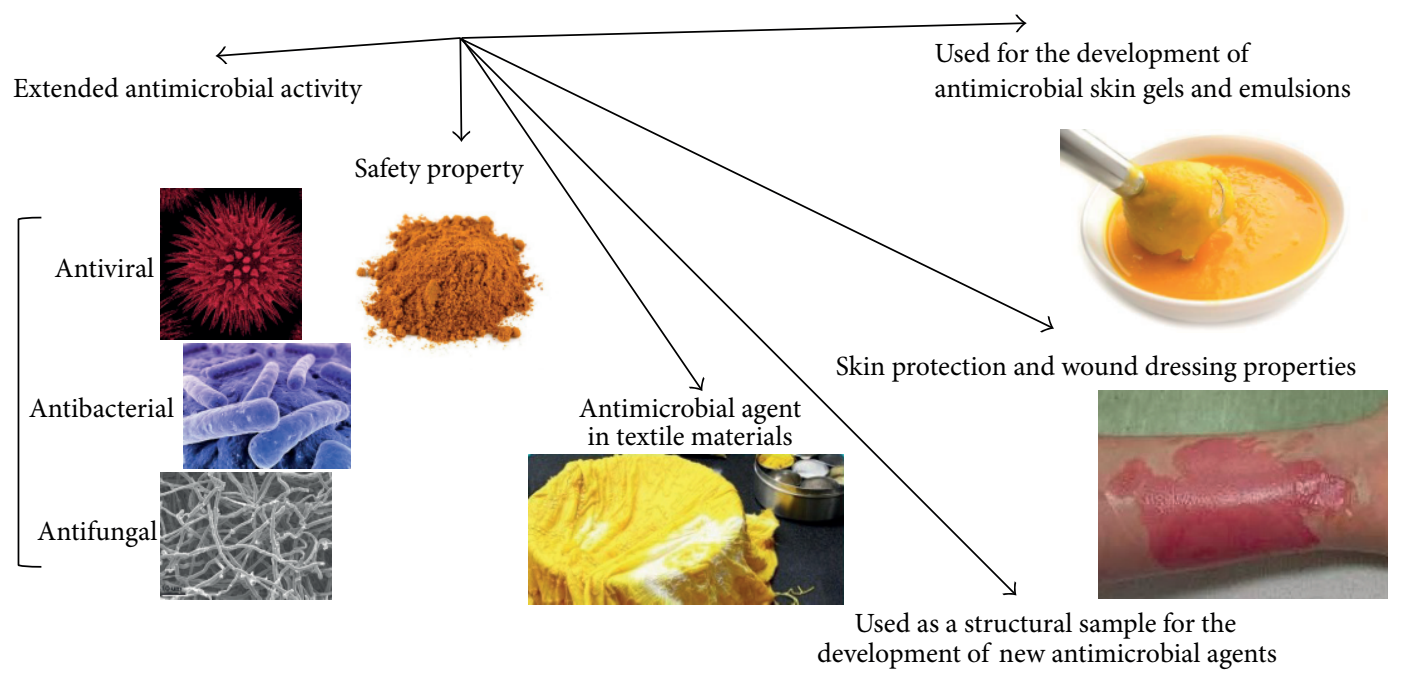

FIGURE 2: Importance of curcumin in antimicrobial studies.

therapeutic index than conventional triple therapy of $H$. pylori on MMP-3 and MMP-9 via reduction of activator protein-1 and proinflammatory molecule activation in $H$. pylori infected gastric tissues [43]. In vivo study of antibacterial effect of curcumin on $H$. pylori compared to OAM (Omeprazole, Amoxicillin, and Metronidazole) treatment revealed poor activity for eradication of $H$. pylori (5.9\% versus $78.9 \%$ for OAM treatment). The reduction in inflammatory cytokine production was not reported from pylori-infected patients treated with curcumin [44]. The in vivo study of 1-week nonantibiotic therapy comprised of curcumin, pantoprazole, $\mathrm{N}$-acetylcysteine, and lactoferrin against $H$. pylori infection was not effective for the eradication of $H$. pylori. However, the decrease in immunological criteria of gastric inflammation and dyspeptic symptoms was reported after 2 months of treatment schedule [45]. Nevertheless, the curcumin administration to the rats with $H$. pylori-induced gastric inflammation revealed a significant reduction in macromolecular leakage and NF- $\kappa \mathrm{B}$ activation [46]. In an in vivo study of $H$. pylori-infected C57BL/6 mice administered with curcumin exhibited immense therapeutic potential and pronounced eradication effect against $H$. pylori infection associated with restoration of gastric damage [41].

2.1. Synergistic Antimicrobial Activity. The outburst of drug resistant microbial strains necessitates the studies for synergistic effects of antibiotics in combination with plant's derivatives to develop the antimicrobial cocktail with a wider spectrum of activity and reduction of adverse side effects of antimicrobial agents. Staph. aureus resistance to the penicillin group of antibiotics is increasing associated with appearance of adverse side effects such as hypersensitivity and anaphylactic reactions [47]. The synergistic activity of curcuminoids and ampicillin combination demonstrated pronounced reduction in the MIC of ampicillin against either clinical strain or Staph. aureus ATCC 25923 strain. Bacteriocin subtilosin isolated from B. amyloliquefaciens in combination with encapsulated curcumin revealed partial synergism against wild-type and nisin sensitive strains of $L$. monocytogenes Scott A [48]. In another in vivo study using $500 \mu \mathrm{g} / \mathrm{disc}$ of curcumin against clinical isolate of Staph. aureus the synergistic activity with antibiotics of cefixime, cefotaxime, vancomycin, and tetracycline was demonstrated [49]. The results proved that consumption of turmeric during the treatment of Staph. aureus infections with these antibiotics especially cefixime can be possibly helpful. Curcumin also demonstrated a synergistic effect in combination with some antibiotics, including ampicillin, oxacillin, and norfloxacin against methicillin-resistant Staph. aureus strain (MRSA) [20]. The synergistic effect of curcumin with ciprofloxacin against MRSA has also been reported, although there is an evidence of its antagonistic activity against S. typhi and $S$. typhimurium in combination with ciprofloxacin $[49,50]$.

Strongly bound metal complexes to antimicrobial agents are introduced as another possible way for synergistic activity of respective antimicrobial agents through elevation of the binding effect of them to the bacterial walls. Complexes of curcumin with cobalt nanoparticles showed increased antibacterial activity against E. coli [51]. Additionally, fabrication of silver nanocomposite films impregnated with curcumin showed the stronger antibacterial activity against E. coli. It was shown that the bactericidal activity of sodium carboxymethyl cellulose silver nanocomposite films (SCMC SNCFs) as an effective antibacterial material was improved by loading of curcumin with SCMC SNCFs [52]. In another in situ investigation, the synergistic effect of curcumin encapsulated chitosan-[poly (vinyl alcohol)] silver nanocomposite films was shown. The novel antimicrobial films with pronounced antimicrobial exhibition against $E$. coli proved to be potential antibacterial material for treating infections or wound dressing [53].

2.2. Anti-Biofilm Activity. Secretion of exopolysaccharide alginate via different stimulators such as aminoglycosides and imipenem consumption caused the increase in biofilm volume of $P$. aeruginosa. Anti-biofilm activity of curcumin 
against two strains of $P$. aeruginosa isolated from deep oropharyngeal swap samples of two cystic fibrosis patients with MIC values of $16 \mu \mathrm{g} / \mathrm{mL}$ was investigated by crystal violet staining method. The curcumin treatment of the strains with MIC concentrations did not reveal noteworthy elevation in biofilm optical density [54]. In addition, in another study curcumin showed the potential for reduction of biofilm initiation genes, inhibition of 31 quorum sensing (QS) genes, and downregulation of virulence factors including acyl homoserine lactone (HSL) production, elastase/protease activity, and pyocyanin biosynthesis. The antimicrobial activities led to reduction of pathogenicity in Arabidopsis thaliana and Caenorhabditis elegans as whole plant and animal infected models with $P$. aeruginosa [7]. The results exhibited that curcumin can be a potential candidate for P. aeruginosa infections in special infections characterized by biofilm formation, although further comprehensive studies are needed for the approval.

In some cases the adverse effects of curcumin against different antibiotics were shown. Ciprofloxacin is the most effective antibiotic against typhoidal and nontyphoidal infection of Salmonella. The main mechanism for antibacterial activity of ciprofloxacin is through SOS response, induction of chromosome fragmentation, and the production of ROS in the bacterial cell. The in vivo and in vitro investigations on curcumin together with ciprofloxacin showed that, through interference with ciprofloxacin activity, it caused an elevation in proliferation of Salmonella typhi and Salmonella enterica serovar Typhimurium (S. typhimurium). Although curcumin could not suppress the ciprofloxacin-induced gyrase inhibition, it protected Salmonella against oxidative burst induced by interferon $\gamma$ (IFN $\gamma$ ) or ciprofloxacin via owing strong antioxidant effect. The results demonstrated the curcumin by suppressing the antibacterial effect of IFN $\gamma$ or ciprofloxacin might increase the Salmonella pathogenesis [55]. The study of curcumin activity in a murine model of typhoid fever exhibited an elevation of Salmonella typhimurium pathogenicity and increased resistance to antimicrobial agents including antimicrobial peptides, nitrogen species, and reactive oxygen. Upregulation of genes involved in antioxidative function like $\mathrm{mntH}$, sitA, and sodA as well as other genes involved in resistance to antimicrobial peptides including $\mathrm{pmrD}$ and pmrHFIJKLM was considered as a possible cause for the mentioned elevated tolerance. Curcumin also induced upregulation effect on SPI2 genes involved in intracellular survival and downregulation activity on SPI1 genes involved for entry within epithelial cells. This information proved that the indiscriminate use of curcumin should probably inhibit the pathogenesis of Salmonella [55]. Additionally, curcumin also at a dose $500 \mu \mathrm{g} /$ disc showed antagonistic activity on the bactericidal effect of nalidixic acid against clinical strain of Staph. aureus investigated by disc diffusion method [49].

\section{Antiviral Activity}

Lack of effective therapeutics for the most of viral diseases, emergence of antiviral drug resistance, and high cost of some antiviral therapies necessitate finding new effective antiviral compounds $[56,57]$. Additionally, the existing antiviral therapies are not always well-tolerated or quite effective and satisfactory [58]. Hence, the increasing requirement for antiviral substances will be more highlighted. Plants as a rich source of phytochemicals with different biological activities including antiviral activities are in interest of scientists [59, 60]. It has been demonstrated that curcumin as a plant derivative has a wide range of antiviral activity against different viruses. Inosine monophosphate dehydrogenase (IMPDH) enzyme due to rate-limiting activity in the de novo synthesis of guanine nucleotides is suggested as a therapeutic target for antiviral and anticancer compounds. Among the 15 different polyphenols, curcumin through inhibitory activity against IMPDH effect in either noncompetitive or competitive manner is suggested as a potent antiviral compound via this process [61]. The study of different bioconjugates of curcumin, namely, di-O-tryptophanylphenylalanine curcumin, di-O-decanoyl curcumin, di-O-pamitoyl curcumin, di-Obis- $(\gamma, \gamma)$ folyl curcumin, $C^{4}$-ethyl- $O-\gamma$-folyl curcumin, and 4-O-ethyl- $O$ - $\gamma$-folyl curcumin, against variety of viruses including parainfluenza virus type 3 (PIV-3), feline infectious peritonitis virus (FIPV), vesicular stomatitis virus (VSV), herpes simplex virus (HSV), flock house virus (FHV), and respiratory syncytial virus (RSV) assessed by MTT test showed the potent antiviral activity of curcumin and its bioconjugates against different viral pathogens for further studies. Also, di-O tryptophanylphenylalanine curcumin and di-O-decanoyl curcumin revealed remarkable antiviral activity against VSV and FIPV/FHV with $\mathrm{EC}_{50}$ values of $0.011 \mu \mathrm{M}$ and $0.029 \mu \mathrm{M}$, respectively. However, bioconjugates did not exhibit significant antiviral activity against $\mathrm{III}_{\mathrm{B}}$ and ROD strains of type 1 human immunodeficiency virus (HIV-1) in MT-4 cells [62]. Table 1 summarizes the antiviral activity of C. longa and curcumin and possible mechanisms underlying inhibitory effects.

Viral long terminal repeat (LTR) has a critical role in transcription of type 1 human immunodeficiency virus (HIV1) provirus. Inhibition of LTR activity can be a possible pathway for antiviral drug candidates in order to block HIV1 replication $[63,64]$. Curcumin proved to be an effective compound to inhibit the HIV-1 LTR-directed gene expression without any major effects on cell viability [24]. Curcumin and its derivatives, namely, reduced curcumin, allyl-curcumin, and tocopheryl-curcumin, revealed $70 \%$ to $85 \%$ inhibition in Tat protein transactivation of HIV-1 LTR measured by $\beta$-galactosidase activities of HeLa cells which in HIV-1 LTR was fused to the indictor of lacZ gene. Tocopheryl-curcumin demonstrated the most inhibition activity with $70 \%$ inhibition at $1 \mathrm{nM}$ compared to $35 \%$ inhibition of curcumin at this concentration [25]. In addition, curcumin inhibited the acetylation of Tat protein of HIV significantly by p300 associated with suppression of HIV-1 multiplication. Curcumin by targeting the acetyltransferase proteins of p300/CREBbinding protein $(\mathrm{CBP})$ can be a potent compound for combinatorial HIV therapeutics [28]. Curcumin was found to be an inhibitor of $\mathrm{HIV}-1$ and $\mathrm{HIV}-2$ protease with $\mathrm{IC}_{50}$ of $100 \mu \mathrm{M}$ and $250 \mu \mathrm{M}$, respectively. The curcumin boron complexes exhibited noteworthy inhibition reduced to the $\mathrm{IC}_{50}$ value of $6 \mu \mathrm{M}$ with time-dependent activity. The elevated affinity of 
TABLE 1: Antiviral activities of Curcuma longa L. and curcumin.

\begin{tabular}{|c|c|c|c|}
\hline Virus & Antiviral substances & Description of antiviral activity type & Reference \\
\hline \multirow{6}{*}{ HIV } & Curcumin & Inhibition of HIV-1 LTR-directed gene expression & {$[24]$} \\
\hline & $\begin{array}{l}\text { Curcumin, reduced curcumin, allyl-curcumin, } \\
\text { tocopheryl-curcumin }\end{array}$ & $\begin{array}{l}\text { Inhibition of Tat-mediated transactivation of HIV-1 } \\
\text { LTR }\end{array}$ & [25] \\
\hline & Curcumin, curcumin boron complexes & Inhibition of HIV-1 and HIV-2 proteases & [26] \\
\hline & Curcumin & Inhibition of HIV-1 Integrase & [27] \\
\hline & Curcumin & Inhibition of Tat protein acetylation & [28] \\
\hline & Curcumin & No antiviral effect in clinical trial & [29] \\
\hline Influenza & Curcumin & Inhibition of haemagglutination & {$[30]$} \\
\hline HSV-1 & Curcumin, gallium-curcumin, $\mathrm{Cu}$-curcumin & Reduction of HSV-1 replication & {$[31,32]$} \\
\hline HSV-2 & Curcumin & Significant protection in mouse model & {$[33]$} \\
\hline Coxsackievirus & Curcumin & Replication inhibition through UPS dysregulation & {$[34]$} \\
\hline $\mathrm{HBV}$ & Aqueous extract & $\begin{array}{l}\text { Suppression of HBV replication by increasing the p } 53 \\
\text { level }\end{array}$ & [35] \\
\hline $\mathrm{HCV}$ & Curcumin & $\begin{array}{l}\text { Decrease of } \mathrm{HCV} \text { replication by suppressing the } \\
\text { Akt-SREBP-1 pathway }\end{array}$ & {$[36]$} \\
\hline $\mathrm{HPV}$ & Curcumin & Inhibition expression of viral oncoproteins of E6 and E7 & {$[37]$} \\
\hline HPV & Curcumin & Downregulation effect on the transcription of HPV-18 & [38] \\
\hline JEV & Curcumin & Reduction in production of infective viral particles & [39] \\
\hline HTLV-1 & Curcumin & $\begin{array}{l}\text { Downregulation of JunD protein in HTLV-1-infected } \\
\text { T-cell lines }\end{array}$ & {$[40]$} \\
\hline
\end{tabular}

boron derivatives of curcumin is possibly associated with the attachment of the orthogonal domains of the compound in intersecting sites within the substrate-binding cavity of the protease [26]. Integrase as another essential enzyme for HIV-1 replication was found to be inhibited by curcumin with $\mathrm{IC}_{50}$ value of $40 \mu \mathrm{M}$. Inhibition of deletion mutant of integrase containing only amino acids 50-212 indicated that curcumin possibly interacts with catalytic core of the enzyme. The study of energy minimization and the structural analogs of curcumin elicited that an intramolecular stacking of two phenyl rings of curcumin is possibly responsible for anti-integrase activity via bringing the hydroxyl groups into close proximity [27]. However, rosmarinic acid and dicaffeoyl methane as two curcumin analogs showed noteworthy inhibitory activity against integrase of HIV-1 with IC $_{50}$ values less than $10 \mu \mathrm{M}$ with the slow rate of binding to the enzyme assessed by kinetic studies [65]. However, through a clinical trial investigation on curcumin as an anti-HIV compound in 40 patients in eight weeks it was shown that there is no reduction in viral load or elevation in CD4 counts. But patients claimed that they preferred to take the curcumin in order to tolerate the minor gastrointestinal sufferings and feel better [29]. This demonstrated that clinical trials can possibly show up with the results completely different from in vitro studies. The clinical trial of clear liquid soap containing $0.5 \% \mathrm{w} / \mathrm{v}$ ethanol extract of C. longa rhizome on HIV patients reduced the wound infections and $100 \%$ decrease in itching symptom and it also affected the abscess to convert to dryness scabs (78.6\%) within 2 weeks [16].

Curcumin showed the anti-influenza activity against influenza viruses PR8, H1N1, and H6N1. The results showed more than $90 \%$ reduction in virus yield in cell culture using $30 \mu \mathrm{M}$ of curcumin. The plaque reduction test elicited the approximate $\mathrm{EC}_{50}$ of $0.47 \mu \mathrm{M}$ for curcumin against influenza viruses [30]. In H1N1 and also H6N1 subtypes, the inhibition of haemagglutinin interaction reflected the direct effect of curcumin on infectivity of viral particles and this has proved by time of drug addiction experiment. Additionally, unlike amantadine, viruses developed no resistance to curcumin. The methoxyl derivatives of curcumin also did not show noteworthy role in the haemagglutination [30]. These results proved the significant potential of curcumin for inhibition of influenza.

In vitro study of curcumin and its derivatives, namely, gallium-curcumin and $\mathrm{Cu}$-curcumin, exhibited remarkable antiviral activity against herpes simplex virus type 1 (HSV-1) in cell culture with $\mathrm{IC}_{50}$ values of $33.0 \mathrm{microg} / \mathrm{mL}$, $13.9 \mathrm{microg} / \mathrm{mL}$, and $23.1 \mathrm{microg} / \mathrm{mL}$, respectively. The $50 \%$ cytotoxic concentration $\left(\mathrm{CC}_{50}\right)$ of the respective compounds on Vero cell line showed to be $484.2 \mu \mathrm{g} / \mathrm{mL}, 255.8 \mu \mathrm{g} / \mathrm{mL}$, and $326.6 \mu \mathrm{g} / \mathrm{mL}$, respectively [31]. Curcumin considerably decreased the immediate early (IE) gene expression and infectivity of HSV-1 in cell culture assays. Curcumin has an effect on recruitment of RNA polymerase II to IE gene promoters through mediation of viral transactivator protein VP16, by an independent process of p300/CBP histone acetyl transferase effect [32]. In vitro replication of HSV-2 could be decreased by curcumin with $\mathrm{ED}_{50}$ value of $0.32 \mathrm{mg} / \mathrm{mL}$ [32]. Moreover, an in vivo study on mouse model with intravaginal HSV-2 challenge showed significant protection against HSV-2 infection due to administration of curcumin. This study showed that curcumin can be a good candidate 
for developing the antiviral products used intravaginally by women for protection against sexually transmitted herpes virus infection [33]. Indeed, a metallo-herbal complex of curcumin with copper $\left(\mathrm{Cu}^{2+}\right)$ demonstrated microbicidal effect for further studies of vaginal gel with antiviral activity [66].

Coxsackieviruses cause a variety of diseases such as dilated cardiomyopathy and myocarditis. Coxsackievirus B3 (CVB3) in spite of extensive investigations is still a major human pathogen without specific effective and approved treatment $[67,68]$. Curcumin exhibited the antiviral activity against coxsackievirus by reduction of viral RNA expression, protein synthesis, and virus titer. In addition, it was found to have a protective effect on cells against virusinduced apoptosis and cytopathic activity. Analysis of different pathways showed that curcumin forced its potent antiviral effect in inhibition of coxsackievirus replication through dysregulation of the ubiquitin-proteasome system (UPS) [34]. The recent studies proved that the UPS-mediated protein modification or degradation is an essential factor in the regulation of coxsackievirus replication [69].

Liver diseases associated with viral infections are major pandemics [70]. The fact that hepatitis B virus (HBV) elevates the possibility for the hepatocellular carcinoma (HCC) development some 100 -fold and 695.900 deaths occurred due to liver cirrhosis and HCC worldwide in 2008 makes the need to find new antivirals against hepatitis viruses [71, 72]. The study of antiviral effect of aqueous extract of Curcuma longa rhizoma against HBV in HepG 2.2.15 cells containing HBV genomes showed repression of HBsAg secretion from liver cells without any cytotoxic effect. It also suppressed the HBV particles production and the rate of mRNA production of $\mathrm{HBV}$ on infected cells. The Curcuma longa extract suppressed $\mathrm{HBV}$ replication by increasing the rate of $\mathrm{p} 53$ protein through enhancing the stability of the protein as well as transactivating the transcription of p53 gene. It was understood that the extract has suppressed HBV enhancer I and X promoter leading to repression of $\mathrm{HBx}$ gene transcription by affecting p53 [35]. In vitro investigation of the antiviral activity of curcumin Huh7 replicon cells expressing the hepatitis C virus $(\mathrm{HCV})$ indicated that curcumin can be a potent antiHCV compound. Results showed the decrease in HCV gene expression and replication through suppressing the AktSREBP-1 pathway. In addition, the mixture of curcumin and IFN $\alpha$ as the known anti-HCV therapy induced profound inhibitory activity on HCV replication and demonstrated that curcumin can be possibly used as a complementary therapy for HCV [36].

High-risk human papillomaviruses (HPVs) infection via the expression of E6 and E7 viral oncoproteins has a critical role for development of cervical carcinoma. Curcumin showed the inhibitory activity against the expression of E6 and E7 genes of HPV-16 and HPV-18 as two main highly oncogenic human papilloma viruses [37]. The transcription factor AP-1 is a critical factor for transcriptional regulation of high-risk HPVs such as HPV-16 and HPV-18. Curcumin downregulates the AP-1 binding activity in HeLa cells with decreasing effect on the transcription of HPV-18 [38]. The results showed that curcumin through apoptosis modulation and also prevention of $\mathrm{NF} \kappa \mathrm{B}$ and $\mathrm{AP}-1$ translocation associated with downregulation of viral oncogenes and decreasing the transcription of HPVs can be a good candidate for the management of highly oncogenic HPV infections [37, 38].

Japanese encephalitis virus (JEV) as an important endemic arbovirus in Southeast Asia is a major cause of acute encephalopathy which generally affects the children and leads to death in one third of patients. The permanent neuropsychiatric sequel is a complication for many survivors from JEV due to ineffective therapeutic measure [73]. The investigation of antiviral activity of curcumin on Neuro2a cell line infected with JEV showed reduction in production of infectious viral particles through inhibition of ubiquitin-proteasome system. The results of in vitro study indicated that curcumin through modulating cellular levels of stress-related proteins, reducing proapoptotic signaling molecules, restoration of cellular membrane integrity, and reduction in reactive oxygen species in cellular level imparts neuroprotection and can be a potential for further investigations [39].

Oncogenesis by human T-cell leukemia virus type 1 as an etiologic factor of adult T-cell leukemia (ATL) is critically dependent on the activation of the activator protein 1 (AP1) [74]. The DNA binding and transcriptional effect of AP-1 in HTLV-1-infected T-cell lines were suppressed by curcumin treatment. Curcumin also inhibited the expression of JunD protein as an important factor in AP-1-DNA complex in HTLV-1-infected T-cells as well as HTLV-1 Tax-induced AP1 transcriptional effect. Cell cycle arrest and inducing of apoptosis were found to be possible mechanisms against HTLV-1 replication in infected T-cell line by curcumin. Suppression of AP-1 activity possibly through decreasing the expression of JunD protein is introduced as a possible pathway for anti-ATL activity of curcumin [40].

\section{Antifungal Activity}

Substances and extracts isolated from different natural resources especially plants have always been a rich arsenal for controlling the fungal infections and spoilage. Due to extensive traditional use of turmeric in food products, various researches have been done in order to study the turmeric and curcumin with the aspect of controlling fungal related spoilage and fungal pathogens. The study of addition the turmeric powder in plant tissue culture showed that turmeric at the 0.8 and $1.0 \mathrm{~g} / \mathrm{L}$ had appreciable inhibitory activity against fungal contaminations [75]. The methanol extract of turmeric demonstrated antifungal activity against Cryptococcus neoformans and Candida albicans with MIC values of 128 and $256 \mu \mathrm{g} / \mathrm{mL}$, respectively [16]. The study of hexane extract of C. longa at $1000 \mathrm{mg} / \mathrm{L}$ demonstrated antifungal effect against Rhizoctonia solani, Phytophthora infestans, and Erysiphe graminis. It was also shown that $1000 \mathrm{mg} / \mathrm{L}$ of ethyl acetate extract of C. longa exhibitedinhibitory effect against $R$. solani, $P$. infestans, Puccinia recondita, and Botrytis cinerea. Curcumin at $500 \mathrm{mg} / \mathrm{L}$ also showed antifungal activity against $R$. solani, Pu. recondita, and $P$. infestans [76]. Curcumin and turmeric oil exert antifungal effect against two phytophagous fungi, namely, Fusarium solani and Helminthosporium oryzae. Turmeric oil exhibited 
the most effective antifungal activity against $F$. solani and $H$. oryzae with $\mathrm{IC}_{50}$ of 19.73 and $12.7 \mu \mathrm{g} / \mathrm{mL}$, respectively [77]. The crude methanol extract of $C$. longa has inhibitory effect against some clinical isolates of dermatophytes. It was demonstrated that 18-month-old and freshly distilled oil isolated from rhizome of C. longa showed the most potent antifungal effect against 29 clinical isolates of dermatophytes with MIC values of 7.2 and $7.8 \mathrm{mg} / \mathrm{mL}$, respectively [78]. Trichophyton rubrum, T. mentagrophytes, Epidermophyton floccosum, and Microsporum gypseum were suppressed by 1:40-1:320 dilutions of turmeric oil. An in vivo study on infected guinea pigs with T. rubrum demonstrated that dermal application of turmeric oil (dilution 1:80) induced an improvement in healing of the lesions after 2-5 days and it caused the lesions after 6-7 days of consumption to vanish. Turmeric oil also showed activity against pathogenic molds such as Sporothrix schenckii, Exophiala jeanselmei, Fonsecaea pedrosoi, and Scedosporium apiospermum with MIC values of $114.9,459.6,459.6$, and $114.9 \mu \mathrm{g} / \mathrm{mL}$, respectively [79]. However, curcumin showed more significant effect against Paracoccidioides brasiliensis than fluconazole, although it did not affect the growth of Aspergillus species [80]. The possible mechanism underlying the mentioned antifungal effect was found to be downregulation of $\Delta^{5,6}$ desaturase (ERG3) leading to significant reduction in ergosterol of fungal cell. Reduction in production of ergosterol results in accumulations of biosynthetic precursors of ergosterol which leads to cell death via generation of ROS [81]. Reduction in proteinase secretion and alteration of membrane-associated properties of ATPase activity are other possible critical factors for antifungal activity of curcumin [82].

Resistant strain development among the Candida species against existing antifungal drugs became a critical problem for therapeutic strategies. Thereby, finding new anti-Candida substances seems to be crucial [83]. The study of curcumin against 14 strains of Candida including 4 ATCC strains and 10 clinical isolates showed that curcumin is a potent fungicide compound against Candida species with MIC values range from 250 to $2000 \mu \mathrm{g} / \mathrm{mL}$ [82]. In another study, anti-Candida activity of curcumin was demonstrated against 38 different strains of Candida including some fluconazole resistant strains and clinical isolates of C. albicans, C. glabrata, C. krusei, C. tropicalis, and C. guilliermondii. The MIC ${ }_{90}$ values for sensitive and resistant strains were 250-650 and 250$500 \mu \mathrm{g} / \mathrm{mL}$, respectively. Intracellular acidification via inhibition of $\mathrm{H}^{+}$-extrusion was identified as possible mechanism for cell death of Candida species [84]. The development of hyphae was proved to be inhibited by curcumin through targeting the global suppressor thymidine uptake 1 (TUP1) [81, 85]. Curcumin also showed inhibitory effect on Cryptococcus neoformans and C. dubliniensis with MIC value of $32 \mathrm{mg} / \mathrm{L}$ [80]. One of the major complications during therapies against chronic asthma is oropharyngeal candidiasis. Curcumin as a potential candidate for the treatment of candidosis with anti-inflammatory activity was studied in a murine model of asthma. Oral administrator of Curcumin is more effective than dexamethasone in reducing fungal burden in $\mathrm{BALB} / \mathrm{c}$ mice. It also significantly decreased pathological changes in asthma [86]. Adhesion of Candida species isolated from AIDS patients to buccal epithelial cells is also markedly inhibited by curcumin and it was found to be more effective compared to fluconazole [80].

The investigation of curcumin mediation for photodynamic therapy can reduce the biofilm biomass of C. albicans, C. glabrata, and C. tropicalis. The results demonstrated that association of four LED fluences for light excitation with $40 \mu \mathrm{M}$ concentration of curcumin at $18 \mathrm{~J} / \mathrm{cm}^{2}$ inhibited up to $85 \%$ metabolic activity of the tested Candida species. The use of curcumin with light proved to be an effective method for noteworthy improvement in the antifungal activity against planktonic form of the yeasts [87]. Photodynamic effect considerably decreased C. albicans viability in either planktonic or biofilm cultures probably through increasing the uptake of curcumin by cells. However, to a lesser extent, photodynamic therapy was found to be phototoxic to the macrophages. [88]. A study on a murine model of oral candidiasis was done for gathering reliable data for curcumin-mediated photodynamic therapy efficacy in vivo. Results proved that all exposures to curcumin with LED light markedly inhibited the C. albicans viability after photodynamic therapy without harming the host tissue of mice. However, $80 \mu \mathrm{M}$ of curcumin in association with light showed the best decrease in colony counts of C. albicans [89]. These results showed that curcumin is a high potential photosensitizer compound for fungicidal photodynamic therapy especially against Candida species.

The strong antifungal activity of $C$. longa rhizome and its low side effect were the main reasons to investigate its probable synergistic effect with existing fungicides. The synergistic activity of curcumin with five azole and two polyene drugs including voriconazole, itraconazole, ketoconazole, miconazole, fluconazole, amphotericin B, and nystatin showed 1035-fold reduction in the MIC values of the fungicides against 21 clinical isolates of $C$. albicans. The synergistic activity of curcumin with amphotericin B and fluconazole could be associated with the accumulation of ROS which will be suppressed by adding an antioxidant [85]. The study of $200 \mathrm{clini}-$ cal isolates of Candida species including C. tropicalis, C. kefyr, C. krusei, C. guilliermondii, C. glabrata, C. parapsilosis, and C. albicans demonstrated fungicidal activity for curcumin with MIC value of $32-128 \mu \mathrm{g} / \mathrm{mL}$. Combination of curcumin with amphotericin $\mathrm{B}$ also exhibited synergistic activity against tested Candida species, although fluconazole and curcumin in some cases showed additive effects rather than synergistic activity. These results proved that combination of curcumin with existing fungicidal agents can provide more significant effect against systemic fungal infections like candidemia and candidosis [90]. In silico analysis demonstrated that curcumin by attaching to albumin serum in a separate binding site of amphotericin B and forming the complex alleviated the adverse side effect of amphotericin B via delaying the red cell lysis. The stability and aqueous solubility of the complex of curcumin and amphotericin B with albumin serum can be a potential candidate for the treatment of visceral leishmaniasis and systemic fungal infections [91]. The in vivo study of combination of curcumin and piperine in 
murine model of Candida infection also revealed synergistic effect with noteworthy fungal load reduction in kidney of Swiss mice [85]. The mixture of curcumin and ascorbic acid against different strains of Candida also exhibited 5- to 10-fold reduction of MIC values compared to the time that curcumin was tested alone [92]. These synergistic effects showed that curcumin in combination with different fungicide materials can significantly elicit synergistic activity to enhance the efficacy of existing antifungal strategies.

\section{Enhancing the Bioavailability and Solubility of Curcumin to Improve Antimicrobial Activities}

The optimum potential of curcumin is limited because of poor oral bioavailability and insufficient solubility in aqueous solvents leading to poor absorption, fast metabolism, and quick systemic elimination $[5,93]$. For overcoming this obstacle, nanocarriers like curcumin-loaded PLGA (poly lactideco-glycolide) and curcumin nanoparticle formulation were investigated and their better bioactivity and bioavailability as well as increased cellular uptake compared to curcumin were reported [5]. Another study revealed that heat-extracted curcumin elevated the solubility of curcumin 12-fold without significant disintegration due to heat treatment. Modification of 4-hydroxy-2-nonenal (HNE) as a critical oxidation byproduct involved in disease pathogenesis via cytotoxicity, genotoxicity, and mutagenicity is inhibited $80 \%$ by heatsolubilized curcumin and suggested a possible mechanism for inducing bioactivity of curcumin [94]. The study of nanocurcumin as a nanoparticle of curcumin with the size of $2-40 \mathrm{~nm}$ processed by a wet-milling technique, showed curcumin to be more freely dispersible in water leading to more significant antimicrobial activity against Staph. aureus, E. coli, P. aeruginosa, B. subtilis, and two fungi of $P$. notatum and A. niger due to reduced particle size and enhanced bioavailability $[95,96]$. However, nanocurcumin demonstrated more noteworthy activity against Gram-positive bacteria rather than Gramnegatives [95]. In another study to improve the stability and solubility of curcumin, microencapsulation process was investigated. Microcapsule of curcumin with improved solubility is suitable as a preservative and colorant in food industry and it exhibited potent antimicrobial effect against food-borne pathogens including E. coli, Staph. aureus, B. subtilis, B. cereus, Yersinia enterocolitica, Penicillium notatum, and Saccharomyces cerevisiae with MIC values ranging from 15.7 to $250 \mu \mathrm{g} / \mathrm{mL}$. It was demonstrated that Gram-positive bacteria were more susceptible to the microcapsulated curcumin compared to Gram-negatives. However, antifungal effect was found to be stronger than the bactericidal effect $[97,98]$.

\section{Conclusion}

All previous investigations have shown the extensive antimicrobial activity of curcumin, although in vivo studies in some cases reported the less effective results of curcumin inhibitory effect. Among all former studies on antibacterial activity of curcumin the most promising result is against Helicobacter pylori, at least for using the curcumin as a complementary compound in combination with other existing medicines to decrease the symptoms of gastritis. The extensive antiviral effects of curcumin against different viral pathogens nominate this compound as an antiviral drug candidate to develop new antivirals from natural resources against sensitive viruses especially by developing different curcumin derivatives. However, using curcumin or its derivatives as antiviral compounds needs further investigations. Regarding the studies on antifungal activities of curcumin the most significant effect was found against Candida species and Paracoccidioides brasiliensis, although curcumin revealed fungicide effect against various fungi. In spite of various biological activities of curcumin, no real clinical uses have been reported for this compound and still clinical trials are undergoing for different ailments and diseases, namely, colon and pancreatic cancers, multiple myeloma, myelodysplastic syndromes, Alzheimer, and psoriasis [99]. Until 2013, more than 65 clinical trials on curcumin have been carried out, and still more is underway. This polyphenol compound is now used as a supplement in several countries, namely, China, India, Japan, Korea, South Africa, the United States, Thailand, and Turkey [100].

\section{Conflict of Interests}

The authors declare that there is no conflict of interests regarding the publication of this paper.

\section{Acknowledgment}

The authors would like to thank University of Malaya for University Malaya Research Flagship Grant (UMRG) (FL00113HTM) and Postgraduate Research Grant (PPP) (PG0052012B).

\section{References}

[1] H. P. T. Ammon and M. A. Wahl, "Pharmacology of Curcuma longa," Planta Medica, vol. 57, no. 1, pp. 1-7, 1991.

[2] P. K. Lai and J. Roy, "Antimicrobial and chemopreventive properties of herbs and spices," Current Medicinal Chemistry, vol. 11, no. 11, pp. 1451-1460, 2004.

[3] R. K. Maheshwari, A. K. Singh, J. Gaddipati, and R. C. Srimal, "Multiple biological activities of curcumin: a short review," Life Sciences, vol. 78, no. 18, pp. 2081-2087, 2006.

[4] H. Hayakawa, Y. Minanyia, K. Ito, Y. Yamamoto, and T. Fukuda, "Difference of curcumin content in Curcuma longa L., (Zingiberaceae) caused by Hybridization with other Curcuma species," American Journal of Plant Sciences, vol. 2, no. 2, pp. 111-119, 2011.

[5] P. Anand, H. B. Nair, B. Sung et al., "Design of curcumin-loaded PLGA nanoparticles formulation with enhanced cellular uptake, and increased bioactivity in vitro and superior bioavailability in vivo," Biochemical Pharmacology, vol. 79, no. 3, pp. 330-338, 2010.

[6] C. A. C. Araújo and L. L. Leon, "Biological activities of Curcuma longa L," Memorias do Instituto Oswaldo Cruz, vol. 96, no. 5, pp. 723-728, 2001. 
[7] T. Rudrappa and H. P. Bais, "Curcumin, a known phenolic from Curcuma longa, attenuates the virulence of Pseudomonas aeruginosa $\mathrm{PAO} 1$ in whole plant and animal pathogenicity models," Journal of Agricultural and Food Chemistry, vol. 56, no. 6, pp. 1955-1962, 2008.

[8] P. LaColla, E. Tramontano, C. Musiu, M. E. Marongiu, E. Novellino, and G. Greco, "Curcumin-like derivatives with potent activity against HIV-1 integrase: synthesis, biological evaluation and molecular modeling," Antiviral Research, vol. 37, no. 3, pp. 57-57, 1998.

[9] P. Anand, A. B. Kunnumakkara, R. A. Newman, and B. B. Aggarwal, "Bioavailability of curcumin: problems and promises," Molecular Pharmaceutics, vol. 4, no. 6, pp. 807-818, 2007.

[10] L. Ammayappan and J. Jeyakodi Moses, "Study of antimicrobial activity of aloevera, chitosan, and curcumin on cotton, wool, and rabbit hair," Fibers and Polymers, vol. 10, no. 2, pp. 161-166, 2009.

[11] S. Han and Y. Yang, "Antimicrobial activity of wool fabric treated with curcumin," Dyes and Pigments, vol. 64, no. 2, pp. 157161, 2005.

[12] K. Varaprasad, K. Vimala, S. Ravindra, N. Narayana Reddy, G. Venkata Subba Reddy, and K. Mohana Raju, "Fabrication of silver nanocomposite films impregnated with curcumin for superior antibacterial applications," Journal of Materials Science: Materials in Medicine, vol. 22, no. 8, pp. 1863-1872, 2011.

[13] C. H. Liu and H. Y. Huang, "Antimicrobial activity of curcuminloaded myristic acid microemulsions against Staphylococcus epidermidis," Chemical and Pharmaceutical Bulletin, vol. 60, no. 9, pp. 1118-1124, 2012.

[14] R. Wise, T. Hart, O. Cars et al., "Antimicrobial resistance. Is a major threat to public health," British Medical Journal, vol. 317, no. 7159, pp. 609-610, 1998.

[15] N. Niamsa and C. Sittiwet, "Antimicrobial activity of Curcuma longa aqueous extract," Journal of Pharmacology and Toxicology, vol. 4, no. 4, pp. 173-177, 2009.

[16] S. Ungphaiboon, T. Supavita, P. Singchangchai, S. Sungkarak, P. Rattanasuwan, and A. Itharat, "Study on antioxidant and antimicrobial activities of turmeric clear liquid soap for wound treatment of HIV patients," Songklanakarin Journal of Science and Technology, vol. 27, no. 2, pp. 269-578, 2005.

[17] O.-A. Lawhavinit, N. Kongkathip, and B. Kongkathip, "Antimicrobial activity of curcuminoids from Curcuma longa L. on pathogenic bacteria of shrimp and chicken," Kasetsart JournalNatural Science, vol. 44, no. 3, pp. 364-371, 2010.

[18] I. M. Hosny, W. I. El Kholy, H. A. Murad, and R. K. El Dairouty, "Antimicrobial activity of Curcumin upon pathogenic microorganisms during manufacture and storage of a novel style cheese 'Karishcum,' Journal of American Science, vol. 7, pp. 611-618, 2011.

[19] P. S. Negi, G. K. Jayaprakasha, L. J. M. Rao, and K. K. Sakariah, "Antibacterial activity of turmeric oil: a byproduct from curcumin manufacture," Journal of Agricultural and Food Chemistry, vol. 47, no. 10, pp. 4297-4300, 1999.

[20] S. H. Mun, D. K. Joung, Y. S. Kim et al., "Synergistic antibacterial effect of curcumin against methicillin-resistant Staphylococcus aureus," Phytotherapy Research, vol. 19, no. 7, pp. 599-604, 2013.

[21] S. Tajbakhsh, K. Mohammadi, I. Deilami et al., "Antibacterial activity of indium curcumin and indium diacetylcurcumin," African Journal of Biotechnology, vol. 7, no. 21, pp. 3832-3835, 2008.
[22] D. Rai, J. K. Singh, N. Roy, and D. Panda, "Curcumin inhibits FtsZ assembly: an attractive mechanism for its antibacterial activity," Biochemical Journal, vol. 410, no. 1, pp. 147-155, 2008.

[23] S. Kaur, N. H. Modi, D. Panda, and N. Roy, "Probing the binding site of curcumin in Escherichia coli and Bacillus subtilis FtsZ-a structural insight to unveil antibacterial activity of curcumin," European Journal of Medicinal Chemistry, vol. 45, no. 9, pp. 4209-4214, 2010.

[24] C. J. Li, L. J. Zhang, B. J. Dezube, C. S. Crumpacker, and A. B. Pardee, "Three inhibitors of type 1 human immunodeficiency virus long terminal repeat-directed gene expression and virus replication," Proceedings of the National Academy of Sciences of the United States of America, vol. 90, no. 5, pp. 1839-1842, 1993.

[25] S. Barthelemy, L. Vergnes, M. Moynier, D. Guyot, S. Labidalle, and E. Bahraoui, "Curcumin and curcumin derivatives inhibit Tat-mediated transactivation of type 1 human immunodeficiency virus long terminal repeat," Research in Virology, vol. 149, no. 1, pp. 43-52, 1998.

[26] Z. Sui, R. Salto, J. Li, C. Craik, and P. R. Ortiz de Montellano, "Inhibition of the HIV-1 and HIV-2 proteases by curcumin and curcumin boron complexes," Bioorganic \& Medicinal Chemistry, vol. 1, no. 6, pp. 415-422, 1993.

[27] A. Mazumder, K. Raghavan, J. Weinstein, K. W. Kohn, and Y. Pommier, "Inhibition of human immunodeficiency virus type1 integrase by curcumin," Biochemical Pharmacology, vol. 49, no. 8, pp. 1165-1170, 1995.

[28] K. Balasubramanyam, R. A. Varier, M. Altaf et al., "Curcumin, a novel p300/CREB-binding protein-specific inhibitor of acetyltransferase, represses the acetylation of histone/nonhistone proteins and histone acetyltransferase-dependent chromatin transcription," The Journal of Biological Chemistry, vol. 279, no. 49, pp. 51163-51171, 2004.

[29] J. S. James, "Curcumin: clinical trial finds no antiviral effect," AIDS Treatment News, no. 242, pp. 1-2, 1996.

[30] D.-Y. Chen, J.-H. Shien, L. Tiley et al., "Curcumin inhibits influenza virus infection and haemagglutination activity," Food Chemistry, vol. 119, no. 4, pp. 1346-1351, 2010.

[31] K. Zandi, E. Ramedani, K. Mohammadi et al., "Evaluation of antiviral activities of curcumin derivatives against HSV-1 in Vero cell line," Natural Product Communications, vol. 5, no. 12, pp. 1935-1938, 2010.

[32] S. B. Kutluay, J. Doroghazi, M. E. Roemer, and S. J. Triezenberg, "Curcumin inhibits herpes simplex virus immediate-early gene expression by a mechanism independent of p300/CBP histone acetyltransferase activity," Virology, vol. 373, no. 2, pp. 239-247, 2008.

[33] K. Z. Bourne, N. Bourne, S. F. Reising, and L. R. Stanberry, "Plant products as topical microbicide candidates: assessment of in vitro and in vivo activity against herpes simplex virus type 2," Antiviral Research, vol. 42, no. 3, pp. 219-226, 1999.

[34] X. Si, Y. Wang, J. Wong, J. Zhang, B. M. McManus, and H. Luo, "Dysregulation of the ubiquitin-proteasome system by curcumin suppresses coxsackievirus B3 replication," Journal of Virology, vol. 81, no. 7, pp. 3142-3150, 2007.

[35] H. J. Kim, H. S. Yoo, J. C. Kim et al., "Antiviral effect of Curcuma longa Linn extract against hepatitis B virus replication," Journal of Ethnopharmacology, vol. 124, no. 2, pp. 189-196, 2009.

[36] K. Kim, K. H. Kim, H. Y. Kim, H. K. Cho, N. Sakamoto, and J. Cheong, "Curcumin inhibits hepatitis $\mathrm{C}$ virus replication via suppressing the Akt-SREBP-1 pathway," FEBS Letters, vol. 584, no. 4, pp. 707-712, 2010. 
[37] C. S. Divya and M. R. Pillai, "Antitumor action of curcumin in human papillomavirus associated cells involves downregulation of viral oncogenes, prevention of NFkB and AP-1 translocation, and modulation of apoptosis," Molecular Carcinogenesis, vol. 45, no. 5, pp. 320-332, 2006.

[38] B. K. Prusty and B. C. Das, "Constitutive activation of transcription factor AP-1 in cervical cancer and suppression of human papillomavirus (HPV) transcription and AP-1 activity in HeLa cells by curcumin," International Journal of Cancer, vol. 113, no. 6, pp. 951-960, 2005.

[39] K. Dutta, D. Ghosh, and A. Basu, "Curcumin protects neuronal cells from japanese encephalitis virus-mediated cell death and also inhibits infective viral particle formation by dysregulation of ubiquitin-proteasome system," Journal of Neuroimmune Pharmacology, vol. 4, no. 3, pp. 328-337, 2009.

[40] M. Tomita, H. Kawakami, J.-N. Uchihara et al., "Curcumin suppresses constitutive activation of AP-1 by downregulation of JunD protein in HTLV-1-infected T-cell lines," Leukemia Research, vol. 30, no. 3, pp. 313-321, 2006.

[41] R. De, P. Kundu, S. Swarnakar et al., "Antimicrobial activity of curcumin against helicobacter pylori isolates from India and during infections in mice," Antimicrobial Agents and Chemotherapy, vol. 53, no. 4, pp. 1592-1597, 2009.

[42] A. Foryst-Ludwig, M. Neumann, W. Schneider-Brachert, and M. Naumann, "Curcumin blocks NF- $\kappa \mathrm{B}$ and the motogenic response in Helicobacter pylori-infected epithelial cells," Biochemical and Biophysical Research Communications, vol. 316, no. 4, pp. 1065-1072, 2004.

[43] P. Kundu, R. De, I. Pal, A. K. Mukhopadhyay, D. R. Saha, and S. Swarnakar, "Curcumin alleviates matrix metalloproteinase3 and -9 activities during eradication of Helicobacter pylori infection in cultured cells and mice," PLoS ONE, vol. 6, no. 1, Article ID e16306, 2011.

[44] C. Koosirirat, S. Linpisarn, D. Changsom, K. Chawansuntati, and J. Wipasa, "Investigation of the anti-inflammatory effect of Curcuma longa in Helicobacter pylori-infected patients," International Immunopharmacology, vol. 10, no. 7, pp. 815-818, 2010.

[45] F. Di Mario, L. G. Cavallaro, A. Nouvenne et al., "A curcuminbased 1-week triple therapy for eradication of Helicobacter pylori infection: something to learn from failure?" Helicobacter, vol. 12, no. 3, pp. 238-243, 2007.

[46] K. Sintara, D. Thong-Ngam, S. Patumraj, N. Klaikeaw, and T. Chatsuwan, "Curcumin suppresses gastric NF- $\kappa \mathrm{B}$ activation and macromolecular leakage in Helicobacter pylori-infected rats," World Journal of Gastroenterology, vol. 16, no. 32, pp. 40394046, 2010.

[47] F. C. Odds, "Synergy, antagonism, and what the chequerboard puts between them," Journal of Antimicrobial Chemotherapy, vol. 52, no. 1, p. 1, 2003.

[48] T. Amrouche, K. S. Noll, Y. Wang, Q. Huang, and M. L. Chikindas, "Antibacterial activity of subtilosin alone and combined with curcumin, poly-lysine and zinc lactate against listeria monocytogenes strains," Probiotics and Antimicrobial Proteins, vol. 2, no. 4, pp. 250-257, 2010.

[49] K. M. Moghaddam, M. Iranshahi, M. C. Yazdi, and A. R. Shahverdi, "The combination effect of curcumin with different antibiotics against Staphylococcus aureus," International Journal of Green Pharmacy, vol. 3, no. 2, pp. 141-143, 2009.

[50] S. A. Marathe, R. Kumar, P. Ajitkumar, V. Nagaraja, and D. Chakravortty, "Curcumin reduces the antimicrobial activity of ciprofloxacin against Salmonella Typhimurium and Salmonella
Typhi," Journal of Antimicrobial Chemotherapy, vol. 68, no. 1, pp. 139-152, 2013.

[51] S. Hatamie, M. Nouri, S. K. Karandikar et al., "Complexes of cobalt nanoparticles and polyfunctional curcumin as antimicrobial agents," Materials Science and Engineering C, vol. 32, no. 2, pp. 92-97, 2012.

[52] K. Varaprasad, Y. M. Mohan, K. Vimala, and K. Mohana Raju, "Synthesis and characterization of hydrogel-silver nanoparticlecurcumin composites for wound dressing and antibacterial application," Journal of Applied Polymer Science, vol. 121, no. 2, pp. 784-796, 2011.

[53] K. Vimala, Y. M. Mohan, K. Varaprasad et al., "Fabrication of curcumin encapsulated chitosan-PVA silver nanocomposite films for improved antimicrobial activity," Journal of Biomaterials and Nanobiotechnology, vol. 2, no. 1, pp. 55-64, 2011.

[54] M. Karaman, F. Firıncı, Z. Arıkan Ayyıldız, and I. H. Bahar, "Effects of Imipenem, Tobramycin and Curcumin on biofilm formation of Pseudomonas aeruginosa strains," Mikrobiyoloji Bulteni, vol. 47, no. 1, pp. 192-194, 2013.

[55] S. A. Marathe, S. Ray, and D. Chakravortty, "Curcumin increases the pathogenicity of Salmonella enterica serovar typhimurium in Murine model," PLoS ONE, vol. 5, no. 7, Article ID e11511, 2010.

[56] L. Tomei, S. Altamura, G. Paonessa, R. De Francesco, and G. Migliaccio, "HCV antiviral resistance: the impact of in vitro studies on the development of antiviral agents targeting the viral NS5B polymerase," Antiviral Chemistry \& Chemotherapy, vol. 16, no. 4, pp. 225-245, 2005.

[57] M. Lemoine, S. Nayagam, and M. Thursz, "Viral hepatitis in resource-limited countries and access to antiviral therapies: current and future challenges," Future Virology, vol. 8, no. 4, pp. 371-380, 2013.

[58] E. De Clercq, "Strategies in the design of antiviral drugs," Nature Reviews Drug Discovery, vol. 1, no. 1, pp. 13-25, 2002.

[59] S. A. A. Jassim and M. A. Naji, "Novel antiviral agents: a medicinal plant perspective," Journal of Applied Microbiology, vol. 95, no. 3, pp. 412-427, 2003.

[60] S. Zorofchian Moghadamtousi, M. Hajrezaei, H. Abdul Kadir, and K. Zandi, "Loranthus micranthus Linn.: biological activities and phytochemistry," Evidence-Based Complementary and Alternative Medicine, vol. 2013, Article ID 273712, 9 pages, 2013.

[61] I. Dairaku, Y. Han, N. Yanaka, and N. Kato, "Inhibitory effect of curcumin on IMP dehydrogenase, the target for anticancer and antiviral chemotherapy agents," Bioscience, Biotechnology and Biochemistry, vol. 74, no. 1, pp. 185-187, 2010.

[62] R. K. Singh, D. Rai, D. Yadav, A. Bhargava, J. Balzarini, and E. De Clercq, "Synthesis, antibacterial and antiviral properties of curcumin bioconjugates bearing dipeptide, fatty acids and folic acid," European Journal of Medicinal Chemistry, vol. 45, no. 3, pp. 1078-1086, 2010.

[63] G. J. Nabel, S. A. Rice, D. M. Knipe, and D. Baltimore, "Alternative mechamisms for activation of human immunodeficiency virus enhancer in T cells," Science, vol. 239, no. 4845, pp. 1299$1302,1988$.

[64] B. R. Cullen and W. C. Greene, "Regulatory pathways governing HIV-1 replication," Cell, vol. 58, no. 3, pp. 423-426, 1989.

[65] A. Mazumder, N. Neamati, S. Sunder et al., "Curcumin analogs with altered potencies against HIV-1 integrase as probes for biochemical mechanisms of drug action," Journal of Medicinal Chemistry, vol. 40, no. 19, pp. 3057-3063, 1997. 
[66] G. Chauhan, G. Rath, and A. K. Goyal, "In-vitro anti-viral screening and cytotoxicity evaluation of copper-curcumin complex," Artificial Cells, Nanomedicine and Biotechnology, vol. 41, no. 4, pp. 276-281, 2013.

[67] C. Kawai, "From myocarditis to cardiomyopathy: mechanisms of inflammation and cell death: learning from the past for the future," Circulation, vol. 99, no. 8, pp. 1091-1100, 1999.

[68] C.-K. Lee, K. Kono, E. Haas et al., "Characterization of an infectious cDNA copy of the genome of a naturally occurring, avirulent coxsackievirus B3 clinical isolate," Journal of General Virology, vol. 86, no. 1, pp. 197-210, 2005.

[69] X. Si, B. M. McManus, J. Zhang et al., "Pyrrolidine dithiocarbamate reduces coxsackievirus B3 replication through inhibition of the ubiquitin-proteasome pathway," Journal of Virology, vol. 79, no. 13, pp. 8014-8023, 2005.

[70] D. Ganem and A. M. Prince, "Hepatitis B virus infection-natural history and clinical consequences," The New England Journal of Medicine, vol. 350, no. 11, pp. 1118-1129, 2004.

[71] D. M. Parkin, F. Bray, J. Ferlay, and P. Pisani, "Global cancer statistics, 2002," CA: A Cancer Journal for Clinicians, vol. 55, no. 2, pp. 74-108, 2005.

[72] A. Jemal, F. Bray, M. M. Center, J. Ferlay, E. Ward, and D. Forman, "Global cancer statistics," CA: A Cancer Journal for Clinicians, vol. 61, no. 2, pp. 69-90, 2011.

[73] C.-J. Chen, S.-L. Raung, M.-D. Kuo, and Y.-M. Wang, "Suppression of Japanese encephalitis virus infection by non-steroidal anti-inflammatory drugs," Journal of General Virology, vol. 83, no. 8, pp. 1897-1905, 2002.

[74] M. Fujii, T. Niki, T. Mori et al., "HTLV-1 tax induces expression of various immediate early serum responsive genes," Oncogene, vol. 6, no. 6, pp. 1023-1029, 1991.

[75] R. S. Upendra, P. Khandelwal, and A. H. M. Reddy, “Turmeric powder (Curcuma longa Linn.) as an antifungal agent in plant tissue culture studies," International Journal of Engineering Science, vol. 3, no. 11, pp. 7899-7904, 2011.

[76] M.-K. Kim, G.-J. Choi, and H.-S. Lee, "Fungicidal property of Curcuma longa L. rhizome-derived curcumin against phytopathogenic fungi in a greenhouse," Journal of Agricultural and Food Chemistry, vol. 51, no. 6, pp. 1578-1581, 2003.

[77] H. Chowdhury, T. Banerjee, and S. Walia, "In vitro screening of Curcuma longa $\mathrm{L}$ and its derivatives sa antifungal agents against Helminthosporrum oryzae and Fusarium solani," Pesticide Research Journal, vol. 20, no. 1, pp. 6-9, 2008.

[78] M. Wuthi-udomlert, W. Grisanapan, O. Luanratana, and W. Caichompoo, "Antifungal activity of Curcuma longa grown in Thailand," The Southeast Asian Journal of Tropical Medicine and Public Health, vol. 31, no. 1, pp. 178-182, 2000.

[79] A. Apisariyakul, N. Vanittanakom, and D. Buddhasukh, "Antifungal activity of turmeric oil extracted from Curcuma longa (Zingiberaceae)," Journal of Ethnopharmacology, vol. 49, no. 3, pp. 163-169, 1995.

[80] C. V. B. Martins, D. L. Da Silva, A. T. M. Neres et al., "Curcumin as a promising antifungal of clinical interest," Journal of Antimicrobial Chemotherapy, vol. 63, no. 2, pp. 337-339, 2009.

[81] M. Sharma, R. Manoharlal, N. Puri, and R. Prasad, "Antifungal curcumin induces reactive oxygen species and triggers an early apoptosis but prevents hyphae development by targeting the global repressor TUP1 in Candida albicans," Bioscience Reports, vol. 30, no. 6, pp. 391-404, 2010.

[82] K. Neelofar, S. Shreaz, B. Rimple, S. Muralidhar, M. Nikhat, and L. A. Khan, "Curcumin as a promising anticandidal of clinical interest," Canadian Journal of Microbiology, vol. 57, no. 3, pp. 204-210, 2011.

[83] W. Jianhua and W. Hai, "Antifungal susceptibility analysis of berberine, baicalin, eugenol and curcumin on Candida albicans," Journal of Medical Colleges of PLA, vol. 24, no. 3, pp. 142$147,2009$.

[84] N. Khan, S. Shreaz, R. Bhatia et al., "Anticandidal activity of curcumin and methyl cinnamaldehyde," Fitoterapia, vol. 83, no. 3, pp. 434-440, 2012.

[85] M. Sharma, R. Manoharlal, A. S. Negi, and R. Prasad, "Synergistic anticandidal activity of pure polyphenol curcumin i in combination with azoles and polyenes generates reactive oxygen species leading to apoptosis," FEMS Yeast Research, vol. 10 , no. 5 , pp. 570-578, 2010.

[86] M. Karaman, Z. Arıkan Ayyıldız, F. Firınc1 et al., "Effects of curcumin on lung histopathology and fungal burden in a mouse model of chronic asthma and oropharyngeal candidiasis," Archives of Medical Research, vol. 42, no. 2, pp. 79-87, 2011.

[87] L. N. Dovigo, A. C. Pavarina, J. C. Carmello, A. L. MacHado, I. L. Brunetti, and V. S. Bagnato, "Susceptibility of clinical isolates of Candida to photodynamic effects of curcumin," Lasers in Surgery and Medicine, vol. 43, no. 9, pp. 927-934, 2011.

[88] L. N. Dovigo, A. C. Pavarina, A. P. D. Ribeiro et al., "Investigation of the photodynamic effects of curcumin against Candida albicans," Photochemistry and Photobiology, vol. 87, no. 4, pp. 895-903, 2011.

[89] L. N. Dovigo, J. C. Carmello, C. A. de Souza Costa et al., "Curcumin-mediated photodynamic inactivation of Candida albicans in a murine model of oral candidiasis," Medical Mycology, vol. 51, no. 3, pp. 243-251, 2013.

[90] S.-M. Tsao and M.-C. Yin, "Enhanced inhibitory effect from interaction of curcumin with amphotericin B or fluconazole against Candida species," Journal of Food and Drug Analysis, vol. 8, no. 3, pp. 208-212, 2000.

[91] A. K. Kudva, M. N. Manoj, B. N. Swamy, and C. S. Ramadoss, "Complexation of amphoterecin B and curcumin with serum albumin: solubility and effect on erythrocyte membrane damage," Journal of Experimental Pharmacology, vol. 3, pp. 1-6, 2011.

[92] O. A. K. Khalil, O. M. M. de Faria Oliveira, J. C. R. Vellosa et al., "Curcumin antifungal and antioxidant activities are increased in the presence of ascorbic acid," Food Chemistry, vol. 133, no. 3, pp. 1001-1005, 2012.

[93] C. Mohanty, M. Das, and S. K. Sahoo, "Emerging role of nanocarriers to increase the solubility and bioavailability of curcumin," Expert Opinion on Drug Delivery, vol. 9, no. 11, pp. 13471364, 2012.

[94] B. T. Kurien, A. Singh, H. Matsumoto, and R. H. Scofield, "Improving the solubility and pharmacological efficacy of curcumin by heat treatment," Assay and Drug Development Technologies, vol. 5, no. 4, pp. 567-576, 2007.

[95] B. Bhawana, R. K. Basniwal, H. S. Buttar, V. K. Jain, and N. Jain, "Curcumin nanoparticles: preparation, characterization, and antimicrobial study," Journal of Agricultural and Food Chemistry, vol. 59, no. 5, pp. 2056-2061, 2011.

[96] D. Shailendiran, N. Pawar, A. Chanchal, R. P. Pandey, H. B. Bohidar, and A. K. Verma, "Characterization and antimicrobial activity of nanocurcumin and curcumin," in Proceedings of the International Conference on Nanoscience, Technology and Societal Implications (NSTSI '11), pp. 1-7, IEEE, December 2011. 
[97] Y. Wang, Z. Lu, H. Wu, and F. Lv, "Study on the antibiotic activity of microcapsule curcumin against foodborne pathogens," International Journal of Food Microbiology, vol. 136, no. 1, pp. 71-74, 2009.

[98] Y.-F. Wang, J.-J. Shao, C.-H. Zhou et al., "Food preservation effects of curcumin microcapsules," Food Control, vol. 27, no. 1, pp. 113-117, 2012.

[99] H. Hatcher, R. Planalp, J. Cho, F. M. Torti, and S. V. Torti, "Curcumin: from ancient medicine to current clinical trials," Cellular and Molecular Life Sciences, vol. 65, no. 11, pp. 1631-1652, 2008.

[100] S. C. Gupta, G. Kismali, and B. B. Aggarwal, "Curcumin, a component of turmeric: from farm to pharmacy," Biofactors, vol. 39, no. 1, pp. 2-13, 2013. 

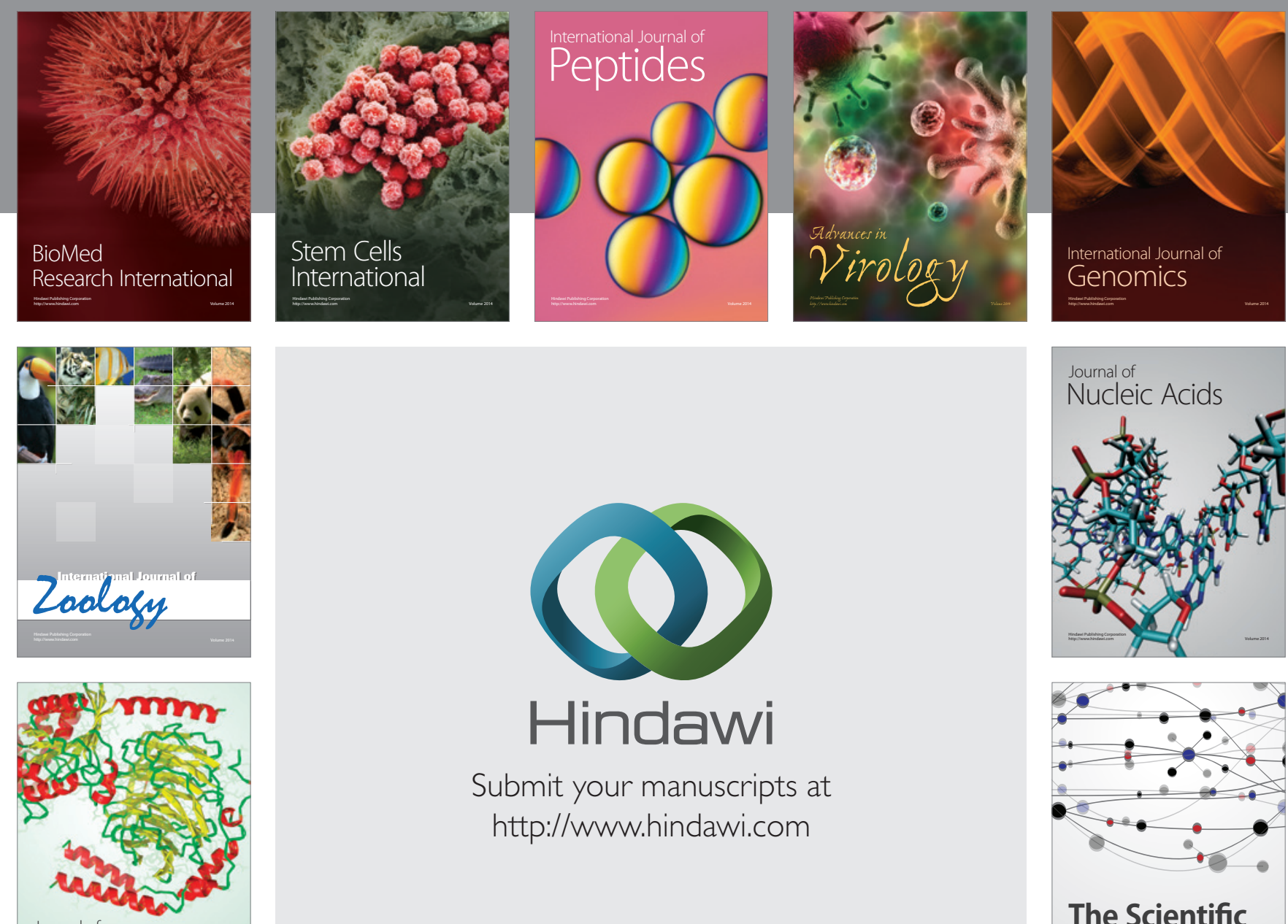

Submit your manuscripts at

http://www.hindawi.com

Journal of
Signal Transduction
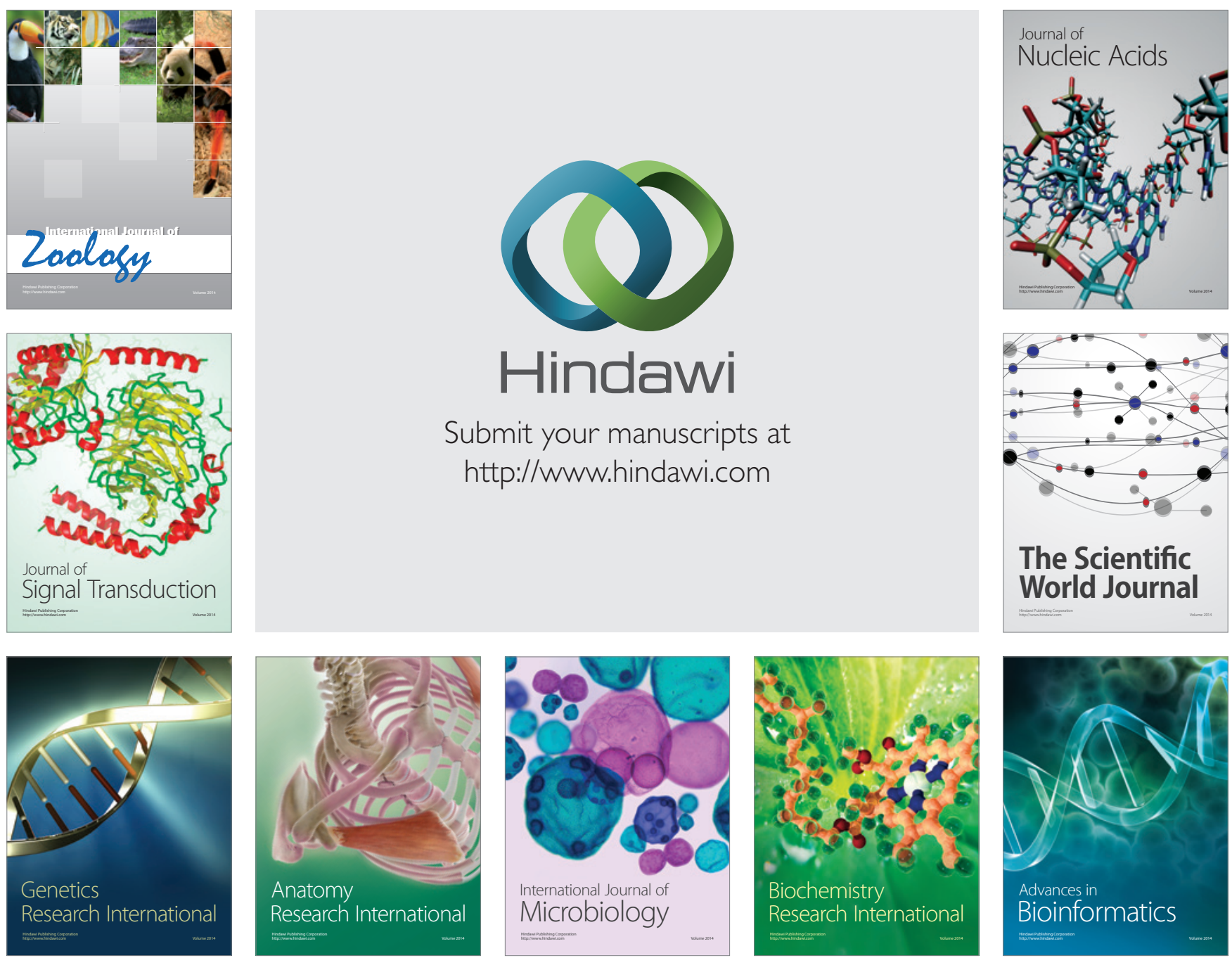

The Scientific World Journal
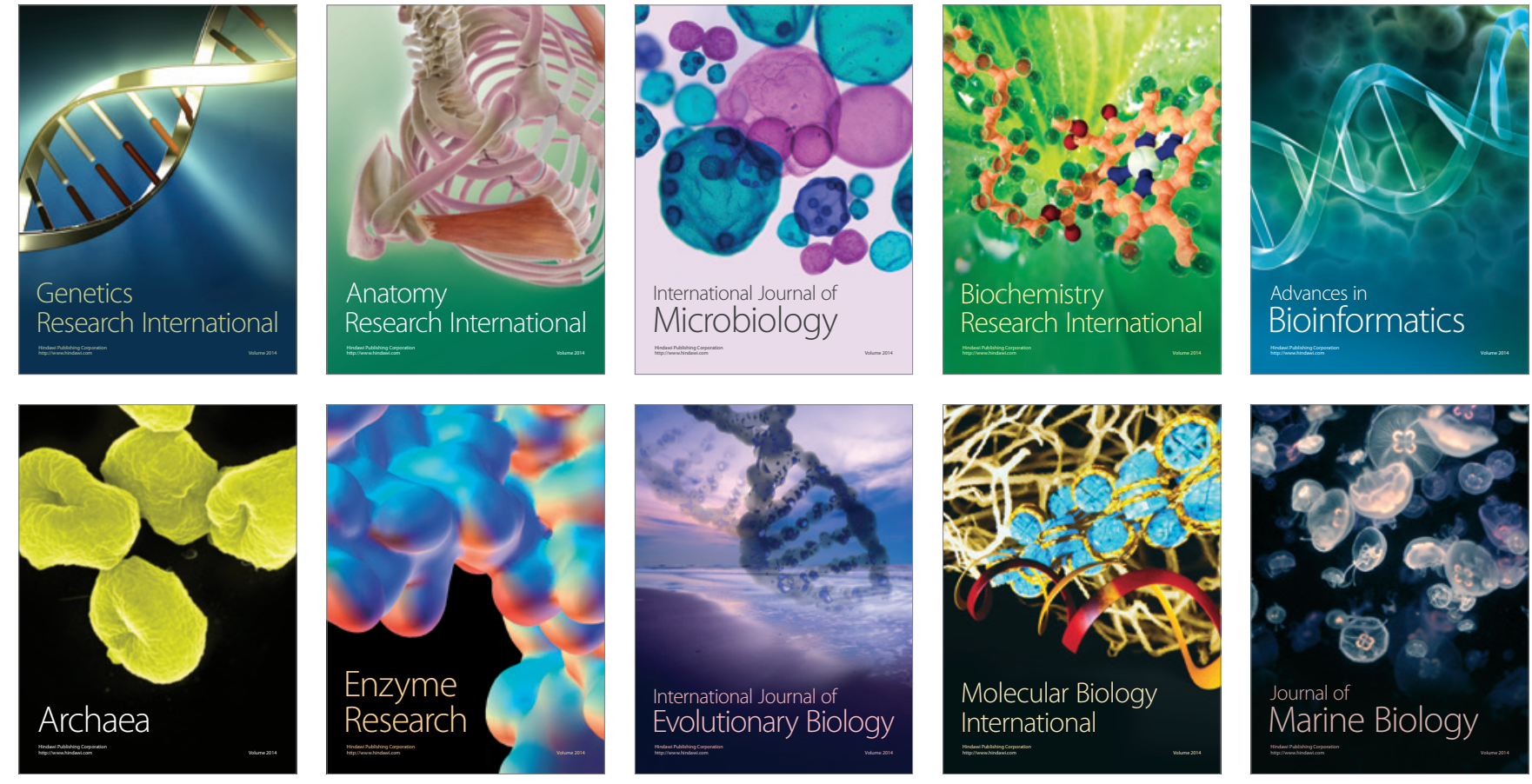